\title{
Variceal bleeding: update of recommendations from the Brazilian Association of Hepatology
}

\author{
Paulo Lisboa BITTENCOURT ${ }^{1}$, Edna STRAUSS ${ }^{2}$, Alberto Queiroz FARIAS ${ }^{3}$, \\ Angelo Alves de MATTOS ${ }^{4}$ and Edmundo Pessoa LOPES $^{5}$
}

ABSTRACT - Since the publication of the Brazilian Association of Hepatology recommendations for the prevention and treatment of variceal bleeding in 2010, new evidence-based data were reported in the literature. This has changed our current management for portal hypertension. This review updates the previous recommendations. It takes the new prognostic staging of cirrhosis into account allowing tailored treatment for advanced fibrosis, compensated or decompensated cirrhosis. An organizing panel of five experts reviewed all recommendations according to available data, which were subsequently scrutinized by all members of the Brazilian Association of Hepatology using a web-based approach. The accepted recommendations are presented in this manuscript.

HEADINGS - Gastrointestinal hemorrhage. Esophageal and gastric varices. Liver cirrhosis. Infection.

\section{INTRODUCTION}

The Brazilian Association of Hepatology published evidencebased recommendations on the management of variceal bleeding (VB) in the April/June 2010 issue of Archives of Gastroenterology following a consensus meeting held in Salvador on May 6th $2009^{(5)}$.

The first version covered the screening of varices and prevention of the first bleeding episode; treatment of acute VB; management of treatment failure; prevention of recurrent bleeding; portal hypertensive gastropathy (PHG); gastric antral vascular ectasia (GAVE); gastric and ectopic varices and schistosomal portal hypertension (PH). Improved understanding of the natural history and prognosis of $\mathrm{PH}$ has led to major changes in definiton, diagnosis, stratification and management of patients with cirrhosis ${ }^{(7,10)}$. This was recently addressed in two evidence-based manuscripts published by the Baveno VI group and the American Association for the Study of Liver Diseases ${ }^{(11,15)}$. Cirrhosis is classified either as compensated (CC) or decompensated (DC). The appearance of clinically relevant events, mainly ascites, VB, hepatic encephalopathy (HE) and infections marks the progression to the decompensated stage ${ }^{(7,10,11,15)}$. Studies on the natural history of cirrhosis have demonstrated different prognoses in patients with $\mathrm{CC}$ according to the presence of varices. In patients with $\mathrm{DC}$, prognosis is related to the occurrence of VB combined with one or more clinical decompensating events, such as ascites, infections or HE (Table 1). It is now well known that $\mathrm{PH}$, defined hemodynamically by a hepatic vein pressure gradient

TABLE 1. New prognostic grading of patients with advanced liver disease (advanced fibrosis or cirrhosis) according to levels of PH, presence of varices and variceal bleeding and other clinical events

\begin{tabular}{|c|c|c|c|c|c|}
\hline \multirow{2}{*}{ Stage } & \multicolumn{5}{|c|}{ Advanced fibrosis or compensated cirrhosis } \\
\hline & 1 & 2 & 3 & 4 & 5 \\
\hline HVPG & $>5 \mathrm{mmHg}$ & $\geq 10 \mathrm{mmHg}$ & $>12 \mathrm{mmHg}$ & $12-20 \mathrm{mmHg}$ & $>20 \mathrm{mmHg}$ \\
\hline Varices & No varices & Varices & \multicolumn{2}{|l|}{ Variceal bleeding } & Any \\
\hline Clinical events & Mild PH & $\mathrm{CSPH}$ & No other events & $\begin{array}{l}\text { Other non-bleeding } \\
\text { events (ascites/HE) }\end{array}$ & 2nd event \\
\hline Mortality ( 5 year) & $1.5 \%$ & $10 \%$ & $20 \%$ & $30 \%$ & $88 \%$ \\
\hline Progression ( 5 year) & $\begin{array}{l}21 \% \text { to stage } 2 \\
1.5 \% \text { to stage } 3 \text { or } 4\end{array}$ & $\begin{array}{l}8 \% \text { to stage } 3 \\
20 \% \text { to stage } 4\end{array}$ & $45 \%$ to stage 5 & \multicolumn{2}{|l|}{$48 \%$ to stage 5} \\
\hline Aims of therapy & $\begin{array}{l}\text { Prevention of } \\
\text { decompensation }\end{array}$ & $\begin{array}{l}\text { Prevention of } \\
\text { decompensation } \\
\text { and variceal bleeding }\end{array}$ & $\begin{array}{l}\text { Control of bleeding } \\
\text { Prevention of } \\
\text { rebleeding and death }\end{array}$ & \multicolumn{2}{|c|}{$\begin{array}{l}\text { Prevention of other clinical events and death } \\
\text { Assessment for liver transplantation }\end{array}$} \\
\hline \multicolumn{6}{|c|}{ PH: portal hypertension; HVPG: hepatic vein pressure gradient; CSPH: clinical significant PH; HE: hepatic encephalopathy. Adapted from references 7,10 and 15.} \\
\hline \multicolumn{6}{|c|}{$\begin{array}{l}\text { Declared conflict of interest of all authors: none } \\
\text { Disclosure of funding: no funding received } \\
{ }^{1} \text { Hospital Português, Salvador, BA, Brasil; }{ }^{2} \text { Hospital do Coração de São Paulo, SP, Brasil; }{ }^{3} \text { Departamento de Gastroenterologia da Faculdade de Medicina da Universidade de São Paulo, SP, } \\
\text { Brasil; }{ }^{4} \text { Universidade Federal de Ciências da Saúde de Porto Alegre e Irmandade da Santa Casa de Misericórdia de Porto Alegre, RS, Brasil; }{ }^{5} \text { Faculdade de Medicina da Universidade } \\
\text { Federal de Pernambuco, PE, Brasil. } \\
\text { Correspondence: Paulo Lisboa Bittencourt. Rua Prof. Clementino Fraga, } 220 \text { / 1901. CEP: 40170-050 - Salvador, BA, Brasil. Email: plbbr@uol.com.br }\end{array}$} \\
\hline
\end{tabular}


(HVPG) $>5 \mathrm{mmHg}$, is the main cause of hepatic decompensation. Mild PH, characterized by HVPG levels $>5 \mathrm{mmHg}$ and $<10$ $\mathrm{mmHg}$ is usually asymptomatic. Clinically significant $\mathrm{PH}(\mathrm{CSPH})$, heralded by the presence of HVPG levels $>10 \mathrm{mmHg}$, can be associated with increased risk or occurrence of clinical events leading to DC. VB, either responsive or refractory to standard therapy, is associated with HVPG levels higher than $12 \mathrm{mmHg}$ and $20 \mathrm{mmHg}$, respectively ${ }^{(7)}$ (Table 1).

Drugs such as traditional non-selective betablockers (NSBB), such as propranolol or nadolol, and NSBB with anti- $\alpha 1$ activity, such as carvedilol, were shown to decrease HVPG levels in patients with cirrhosis. Response to drug therapy, defined as a $20 \%$ decrease in baseline HVPG values or a decrease in HVPG to levels below 12 $\mathrm{mmHg}$, are usually associated with improved survival. Management of patients with cirrhosis differs according to the magnitude of $\mathrm{PH}$, presence of CC or DC and the size of varices. Several interventions categorized in our first consensus document as pre-primary prophylaxis, primary prophylaxis and secondary prophylaxis of VB are no longer endorsed. They are now better classified as strategies for management of: 1) Patients with CC and mild PH; 2) Patients with $\mathrm{CC}$ and $\mathrm{CSPH}$ without varices; 3) Patients with $\mathrm{CC}$ and either small or medium/large varices; 4) Patients with acute VB; 5) Patients who have recovered from $\mathrm{VB}^{(11,15)}$.

Major advances were also notable in the noninvasive diagnosis of $\mathrm{PH}$ and varices screening. However, very scarce new data are available regarding the management of PHG, GAVE and schistosomal PH.

This manuscript updates our previous recommendations for managing VB, taking new evidence-based data and its applicability in Brazil into consideration. An organizing panel of five experts, the same who produced the previous version, reviewed all recommendations according to available data, which were subsequently scrutinized by all members of the Brazilian Association of Hepatology using a web-based approach. The accepted recommendations are presented in this manuscript. Most of these reccomendations are based on new data published since $2010^{(1-33)}$, which are briefly summarized in Figures 1 to 4.

\begin{tabular}{|c|c|c|}
\hline \multicolumn{3}{|c|}{ Screening of varices in patients with cirrhotic portal hypertension } \\
\hline 2010 & Current & Rationale \\
\hline $\begin{array}{l}\text { Screening of varices using endoscopy } \\
\text { Fixed intervals for endoscopic screening }\end{array}$ & $\begin{array}{l}\text { Screening of CSPH using non-invasive methods } \\
\text { Screening of varices using endoscopy } \\
\text { Different intervals for screening according to disease (in)activity }\end{array}$ & $\begin{array}{l}\text { Use of non-invasive methods to rule out CSPH to avoid } \\
\text { endoscopy } \\
\text { Reverst1,12) } \\
\text { Rrogression of portal hypertension }{ }^{(11)}\end{array}$ \\
\hline \multicolumn{3}{|c|}{ Management of patients with compensated cirrhosis and no varices } \\
\hline 2010 & Current & Rationale \\
\hline No role for pre-primary prophylaxis & $\begin{array}{l}\text { According to stage of advanced fibrosis or cirrhosis } \\
\text { No role yet for NSBB } \\
\text { Statins look promising }{ }^{(1)}\end{array}$ & $\begin{array}{l}\text { For prevention of progression it is important to treat the } \\
\text { underlying cause of liver disease, and to recommend } \\
\text { alcohol abstinence and weight control(11,15) }\end{array}$ \\
\hline \multicolumn{3}{|c|}{ Management of patients with cirrhosis and either small or medium/large varices } \\
\hline 2010 & Current & Rationale \\
\hline $\begin{array}{l}\text { According to the size, presence of red signs on } \\
\text { varices and Child-Pugh score either traditional } \\
\text { NSBB or EVL }\end{array}$ & $\begin{array}{l}\text { According to the size, presence of red signs on varices and Child-Pugh } \\
\text { score, either traditional NSBB, EVL or carvedilol can be used } \\
\text { Avoidance of carvedilol in decompensated cirrhosis and caution with } \\
\text { the use of NSBB in refractory ascites } \\
\text { Sta, }{ }^{(3,11,15,19,20,25,26)} \\
\text { Statins are promising } \\
\text { Hepatic vein pressure gradient-guided therapy useful but not widely } \\
\text { available to assess response to NSBB }{ }^{(11,15)}\end{array}$ & $\begin{array}{l}\text { Carvedilol promotes greater reduction of portal } \\
\text { hypertension when compared to propranolol, and is as } \\
\text { efficacious or better than EVL and can be used in patients } \\
\text { unresponsive to traditional NSBB } \\
\text { Simvastatin can lower portal hypertension }\end{array}$ \\
\hline
\end{tabular}

FIGURE 1. Comparison of the 2010 and current recommended strategies for screening and management of patients with portal hypertension. CSPH: clinical significant portal hypertension; EVL: endoscopic variceal ligation; NSBB: non-selective betablockers.

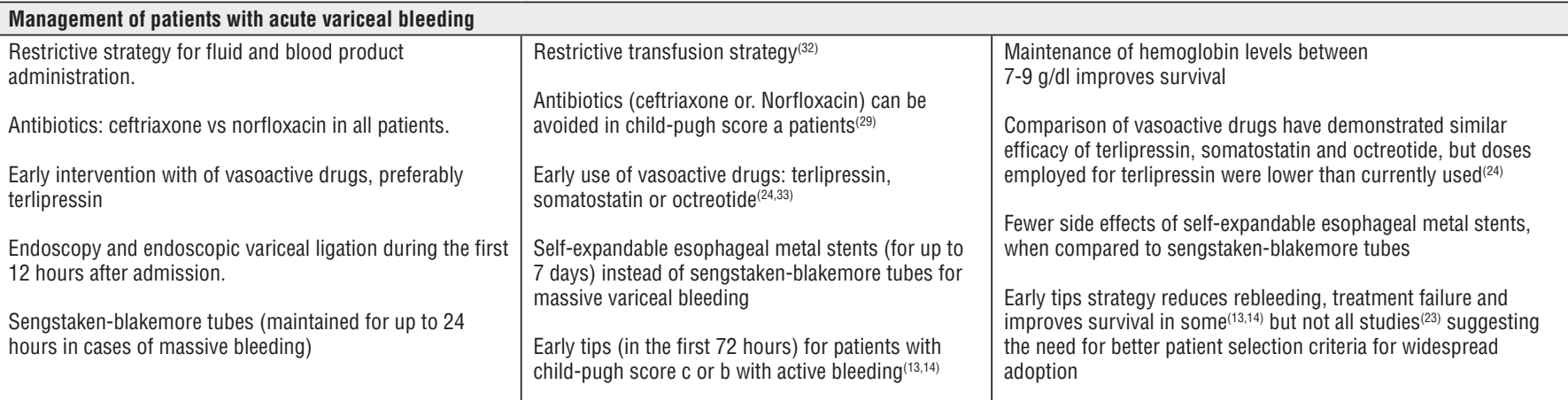

FIGURE 2. Comparison of the 2010 and current recommended strategies for management of patients with acute variceal bleeding.

TIPS: transjugular intrahepatic portosystemic shunt. 


\begin{tabular}{|c|c|c|}
\hline \multicolumn{3}{|l|}{ Prevention of variceal rebleeding } \\
\hline $\begin{array}{l}\text { Traditional non-selective betablockers plus } \\
\text { endoscopic variceal ligation }\end{array}$ & $\begin{array}{l}\text { Traditional non-selective betablockers plus endoscopic variceal } \\
\text { ligation } \\
\text { Carvedilol not currently recommended }{ }^{(11,15)} \\
\text { Propranolol dose must be titrated according to the stage of } \\
\text { liver disease }{ }^{(3,19)} \\
\text { Simvastatin is promising }^{(2)}\end{array}$ & $\begin{array}{l}\text { Non-selective betablockers should be used with caution in } \\
\text { patients with refractory ascites and should be withdrawn in the } \\
\text { presence of hypotension, hyponatremia or acute kidney injury, } \\
\text { because of their detrimental effect on survival } \\
\text { Doses should not be increased beyond } 160 \mathrm{mg} / \text { day in subjects } \\
\text { with large or refractory ascites }{ }^{(3,19)}\end{array}$ \\
\hline
\end{tabular}

FIGURE 3. Comparison of the 2010 and current recommended strategies for prevention of variceal rebleeding.

\begin{tabular}{|c|c|c|}
\hline \multicolumn{3}{|l|}{ Management of portal hypertensive gastropathy } \\
\hline $\begin{array}{l}\text { Vasoactive drugs } \\
\text { Endoscopic therapy with laser or argon plasma } \\
\text { coagulation. } \\
\text { TIPS or surgery in refractory cases }\end{array}$ & $\begin{array}{l}\text { Vasoactive drugs } \\
\text { Endoscopic therapy with laser or argon plasma } \\
\text { coagulation or hemostatic powder }{ }^{(28)} \\
\text { TIPS or even surgery for patients refractory to } \\
\text { treatment }\end{array}$ & $\begin{array}{l}\text { Hemostatic powder can provide a mechanical barrier over the } \\
\text { bleeding point, leading to hemostasis. Experience is too limited. } \\
\text { The value of the technique is yet to be proven. }\end{array}$ \\
\hline \multicolumn{3}{|l|}{ Gastric variceal bleeding } \\
\hline 2010 & Current & Rationale \\
\hline $\begin{array}{l}\text { Endoscopic cyanoacrilate (preferred) } \\
\text { TIPS } \\
\text { BRTO }\end{array}$ & $\begin{array}{l}\text { Endoscopic cyanoacrilate injection (preferred) } \\
\text { TIPS } \\
\text { BRTO } \\
\text { Endoscopic ultrasound-assisted coil deployment } \\
\text { for gastric varices with or without concomitant } \\
\text { cyanoacrylate glue injection for selected patients }\end{array}$ & $\begin{array}{l}\text { Coil provides a special matrix for cyanoacrilate adherence } \\
\text { and theoretically decreases the risk of glue embolization. The } \\
\text { transesophageal approach avoids interference from food or clots } \\
\text { on visualization of fundal varices (few data). }\end{array}$ \\
\hline \multicolumn{3}{|c|}{ Management of portal hypertension in patients with extrahepatic portal vein obstruction } \\
\hline 2010 & Current & Rationale \\
\hline $\begin{array}{l}\text { Anticoagulation } \\
\text { TIPS in selected cases } \\
\text { EVL or cyanacrilate for bleeding varices }\end{array}$ & $\begin{array}{l}\text { Anticoagulation } \\
\text { TIPS in selected cases } \\
\text { EVL or cyanacrilate for bleeding varices Transplenic } \\
\text { approach to perform angioplasty of the thrombosed } \\
\text { portal vein or suction thrombectomy, followed by } \\
\text { embolization of varices and TIPS placement }{ }^{(17,30)}\end{array}$ & $\begin{array}{l}\text { Embolization of gastric varices or shunts may be used for } \\
\text { selected patients with refractory variceal bleeding }\end{array}$ \\
\hline
\end{tabular}

FIGURE 4. Comparison of the 2010 and current recommended strategies for the management of portal hypertension in special situations.

TIPS: transjugular intrahepatic portosystemic shunt; BRTO: balloon occluded retrograde transvenous obliteration; EVL: endoscopic variceal ligation; SCL: sclerotherapy. 


\section{UPDATE OF RECOMMENDATIONS}

\section{Screening of varices in patients with cirrhosis and portal hypertension}

1) Screening for esophageal varices should be carried out for all patients with advanced fibrosis and cirrhosis at risk of $\mathrm{CSPH}$, independently of the severity of liver dysfunction. Non-invasive tests can rule out the presence of CSPH. Liver stiffness (LS) $<20 \mathrm{kPa}$, on two different occasions, determined by transient elastography (TE), coupled with platelet count $>150.000 / \mathrm{mm}^{3}$ can rule out CSPH in patients with viral hepatitis and has the potential to avoid endoscopy for screening of esophageal varices. However, endoscopy is a low cost procedure widely available in most Brazilian centers, whereas TE is more expensive, requires operator expertise and is not currently available or covered in the public healthcare system.

2) Upper digestive endoscopy is the most reliable method for screening.

3) Variceal size should be classified at endoscopy as small $(<3$ $\mathrm{mm})$, medium $(3-5 \mathrm{~mm})$ or large $(>5 \mathrm{~mm})$. The presence of red signs on varices should be recorded.

4) Patients with $\mathrm{CC}$ without varices at baseline should undergo endoscopy every 2 years in the presence of active liver disease or every three years with inactive liver disease (sustained virological response for hepatitis $\mathrm{C}$, undetectable HBV DNA levels under hepatitis B therapy and prolonged alcohol abstinence for alcoholic liver disease).

5) Patients with $\mathrm{CC}$ with small varices at baseline should be submitted to endoscopy every year if liver disease is active or every two years if it is inactive (sustained virological response for hepatitis $\mathrm{C}$, undetectable HBV DNA levels under hepatitis B therapy, or prolonged alcohol abstinence for alcoholic liver disease).

6) Endoscopy should be performed or repeated in the event of decompensation of cirrhosis.

II. Management of patients with CC and mild PH (HVPG $>5$ $\mathrm{mmHg}$ and $<10 \mathrm{mmHg}$ ) and CSPH (HVPG $>10 \mathrm{mmHg}$ ) with no varices

1) HVPG is the most reliable method to detect mild and clinically significant $\mathrm{PH}$, but it is invasive and not routinely available in clinical practice.

2) Clinical, laboratory and ultrasonographic findings in patients with advanced fibrosis and $\mathrm{CC}$ could be valuable to grade $\mathrm{PH}$ as mild or $\mathrm{CSPH}$, but either the absence or the presence of varices at endoscopy are the best available markers to diagnose the presence of mild PH or CSPH in clinical practice.

3) Whenever available, LS $<20 \mathrm{kPa}$, determined by TE and the platelet count $>150,000 / \mathrm{mm}^{3}$ can exclude CSPH. Imaging evidence of portocollateral shunting, reversal of portal blood flow, dilation or reduced velocity of portal vein can diagnose CSPH.

4) Management of patients with mild PH should aim to prevent disease progression to CSPH and decompensation of cirrhosis. Therapy should be targeted towards resolution or suppression of the underlying cause of chronic liver disease.

5) No pharmacological therapy, including NSBB, is currently recommended for mild $\mathrm{PH}$ or CSPH in order to prevent ag- gravation of $\mathrm{PH}$, development of varices or decompensation. NSBB and statins used in combination in this setting has shown promising results in clinical research.

6) Avoidance of alcohol and tobacco, and weight loss measures in obese patients is recommended.

\section{Management of patients with cirrhosis and either small or medium/large varices}

1) Patients with small varices and Child-Pugh A or B cirrhosis without red signs on varices may benefit from primary prophylaxis, but there is insufficient evidence to support a recommendation.

2) Patients with small varices with red signs on varices and/ or advanced cirrhosis (Child-Pugh C) have high risk of bleeding and should be submitted to primary prophylaxis with traditional NSBB or carvedilol.

3) Patients with medium or large varices should be submitted to prophylaxis independently of the presence of advanced liver disease or red signs on varices. Treatment options include traditional NSBB, carvedilol or endoscopic variceal ligation (EVL). Sclerotherapy (SCL) should be proscribed due to its adverse impact on patient survival.

4) Propranolol or nadolol (although no longer commercially available in Brazil) are traditional NSBB that can be used in patients with CC and DC. Propranolol should be used with initial oral doses of 20-40 $\mathrm{mg}$ twice a day, titrated up to $160-320 \mathrm{mg} /$ day to maintain heart rate (HR) between 55-60 bpm and systolic blood pressure $>90 \mathrm{mmHg}$. In patients with ascites, the dose of propranolol should be increased gradually to no more than $160 \mathrm{mg} / \mathrm{day}$, and should be discontinued in patients with large or refractory ascites, acute kidney injury, hyponatremia (Na levels $<130 \mathrm{mEq} / \mathrm{L}$ ) or systolic blood pressure $<90 \mathrm{mmHg}$.

5) Carvedilol should be started in oral doses of $3.125 \mathrm{mg}$ twice a day, and titrated to $6.25 \mathrm{mg}$ twice a day. Doses should not be further increased unless there is evidence of arterial hypertension. Conversely, the dose should be decreased or treatment discontinued if systolic blood pressure falls below $90 \mathrm{mmHg}$. Because Carvedilol lowers systolic blood pressure, caution is required in patients with ascites. It should be avoided in patients with refractory ascites.

6) EVL should be performed every 2-4 weeks until eradication of varices. Endoscopy should be repeated 3 months after eradication and thereafter every 6-12 months.

7) Therapeutic strategy should be tailored according to the patient's characteristics and preferences, contraindications, adverse events, availability of local resources and expertise. Propranolol intolerant patients should be switched either to carvedilol or EVL.

8) There is no rationale for any combination therapy of drugs (propranolol, carvedilol or nitrates), or any of them with EVL, in order to prevent the first VB episode in cirrhosis.

9) There is no need for surveillance endoscopy in patients under primary prophylaxis.

10) HVPG measurement before and after initiation of pharmacological therapy is valuable in assessing hemodynamic response to propranolol or carvedilol, defined as a $20 \%$ decrease in HVPG baseline values, or a decrease to lower than $12 \mathrm{mmHg}$. 


\section{Management of patients with acute VB}

1) Acute VB should be initially managed in the intensive care unit.

2) Fluid resuscitation should be employed with caution in order to maintain hemodynamic stability.

3) Airway protection is advisable for patients with impaired consciousness and massive hematemesis, and those who require Sengstaken-Blakemore $(\mathrm{SB})$ tubes.

4) Use of SB tubes at admission for a maximum of 24 hours should be reserved for cases of massive hemorrhage with hemodynamic compromise and for patients who are not responsive to intravenous fluids, as a bridging therapy until definitive treatment can be administered. Self-expanding covered esophageal metal stents, wherever available, are a safer alternative to SB tubes.

5) Red blood cell transfusions should aim for hemoglobin levels between 7-9 g/dL, but higher hemoglobin levels may be necessary depending on patient's age, comorbidities and ongoing bleeding.

6) INR should not be used to guide transfusional policy. There are no data to support recommendations for management of coagulopathy and thrombocytopenia in patients with cirrhosis.

7) Vasoactive drugs should be started as early as possible, even prior to endoscopy, in patients with suspicion of VB.

8) Terlipressin (TL), somatostatin (SMT) or octreotide (OCT) should be used according to patient's characteristics, and taking cost into account. With currently recommended doses, TL, when compared to SMT or OCT, induces a greater and more sustained decrease in portal pressure. Some studies have shown a beneficial effect on survival when TL is used alone or combined with sclerotherapy (SCL), when compared to placebo or SCL alone. However, more recent data has challenged this finding, and do not demonstrate a clear benefit of any one drug over the others. Use of TL is not advisable in patients with coronary heart disease, severe peripheral vascular disease and uncontrolled arterial hypertension, and the use of vasopressin with or without nitrates should be abandoned in the management of VB.

9) TL should be administered as an intravenous bolus dose of $2 \mathrm{mg}$ followed by 1-2 mg (depending on patient's weight) every 4 hours during the initial 48 hours after admission. The dose should be reduced to a maintenance dose of $1 \mathrm{mg}$ every 4 hours. SMT should be administered as an intravenous bolus dose of $250 \mu \mathrm{g}$ followed by a continuous infusion of $250 \mu \mathrm{g} / \mathrm{h}$. OCT should be administered as an intravenous bolus dose of $50-100 \mu \mathrm{g}$ followed by a continuous infusion of $50 \mu \mathrm{g} / \mathrm{h}$. These drugs should be adminstered for 5 days in order to prevent variceal rebleeding.

10) Upper gastrointestinal endoscopy should ideally be performed during the first 12 hours of bleeding from esophageal varices.

11) Prior to endoscopy, airway protection is recommended in patients with massive bleeding, grades III and IV hepatic encephalopathy or respiratory failure. In the absence of contraindication, $250 \mathrm{mg}$ of intravenous erythromycin over 30-120 minutes should also be administered to improve the visual field of the operator during endoscopy.
12) EVL should be the first choice for the endoscopic treatment, but SCL is an option when EVL is unavailable or technically not feasible.

13) Combined endoscopic and pharmacological treatment with vasoactive drugs is superior to either treatment alone. Combination therapy is recommended for all patients with suspected VB, but pharmacological monotherapy is capable of controlling VB when therapeutic endoscopy is not immediately available. Vasoactive drugs should be administered immediately at admission. If varices are excluded as the source of bleeding, drug therapy must be discontinued.

14) Infections, particularly urinary tract infections, spontaneous bacterial peritonitis and lower respiratory tract infections should be screened for in all patients with VB.

15) Screening for infections should at minimum include blood cultures, ascitic fluid culture and biochemistry tests, urine sediment analysis and chest $\mathrm{X}$ ray.

16) Antibiotic prophylaxis is mandatory, preferably before endoscopy, to reduce the risk of infection, variceal rebleeding and mortality.

17) Oral quinolones, preferably norfloxacin twice a day (400 mg), or third-generation cephalosporin, usually intravenous ceftriaxone $1 \mathrm{~g}$ per day, is recommended up to 7 days. Patients with advanced cirrhosis and/or hemodynamic instability should ideally receive ceftriaxone.

18) Based on current data, there is no evidence to recommend any prophylaxis for hepatic encephalopathy in patients with VB.

19) Even though hypovolemia is the most common cause of acute kidney injury in patients with $\mathrm{VB}$, the possibility of hepatorenal syndrome should be taken into account, and treated with combination of albumin and either terlipressin or norepinephrine.

20) Due to its positive impact on survival, early (transjugular intrahepatic portosystemic shunt) TIPS placement has been recommended for high-risk patients (Child-Pugh $\mathrm{C}$ with 10-13 points or B with active bleeding). However, refinement of these criteria is needed before it can be generally recommended. In this regard, it is important to emphasize that this strategy is unavailable in most Brazilian centers due to its cost and a lack of local operator expertise.

21) In cases of treatment failure, salvage placement of PTFEcovered TIPS should be recommended, but additional endoscopic hemostasis could also be attempted while waiting for TIPS placement, if it is not immediately available.

22) SB tubes or esophageal stents remain options for patients with massive bleeding as a bridging therapy to a definitive treatment.

23) Shunt surgery should be performed only in patients with well-preserved liver function, and if TIPS is unavailable and bleeding is uncontrolled or recurs after the second therapeutic endoscopy.

\section{Prevention of recurrent VB}

1) Combination of traditional NSBB and EVL is recommended for prevention of recurrent VB in patients with cirrhosis. Carvedilol cannot be recommended for prevention of rebleeding at present because it has not been compared to the standard treatment, EVL + traditional NSBB. However, the use of carvedilol and statins for secondary prevention shows potential for future applications. 
2) Propranolol or nadolol (not commercially available in Brazil) are traditional NSBB that can be used in patients with CC and DC. Propranolol should be administered in initial oral doses of 20-40 mg twice a day, titrated up to $160-320 \mathrm{mg} /$ day to maintain heart rate (HR) between 55-60 bpm and systolic blood pressure $>90 \mathrm{mmHg}$. In patients with ascites, the dose of propranolol should be increased gradually to values of no greater than $160 \mathrm{mg} /$ day and should be discontinued in patients with grade III or refractory ascites in the presence of acute kidney injury, hyponatremia ( $\mathrm{Na}$ levels $<130 \mathrm{mEq} / \mathrm{L})$ and systolic blood pressure $<90 \mathrm{mmHg}$.

3) EVL should be performed every 2-4 weeks until variceal eradication is achieved. Endoscopy should be repeated 3 months after eradication and thereafter every 6-12 months.

4) PTFE-covered TIPS is recommended for patients with recurrent bleeding despite undergoing treatment with EVL + traditional NSBB.

5) Surgical shunts should only be considered when TIPS is unavailable. When surgery is required as rescue therapy, selective splenorenal, mesocaval or $8 \mathrm{~mm} \mathrm{H}$-graft portacaval shunts are preferable. The procedure requires a high level of surgical expertise, and should be performed in a specialist center in order to attain positive outcomes. Liver transplantation (LT) is a better treatment option than surgical shunts for patients with high MELD scores.

\section{Management of PHG and gastric antral vascular ectasia (GAVE)}

1) PHG and GAVE are causes of upper gastrointestinal bleeding in patients with cirrhotic or non-cirrhotic $\mathrm{PH}$, They are considered two separate conditions with distinct management options.

2) Due to a lack of data, no recommendations can be drawn for primary prophylaxis of bleeding in PHG.

3) Traditional NSBB and iron supplementation are the frontline treatment for obscure blood losses from PHG.

4) Injection, thermal or mechanical methods of endoscopic therapy may be attempted in patients with PHG or GAVE with treatable lesions identified at endoscopy. The most commonly used method is argon plasma coagulation (APC), but hemostatic powder, clips and band ligation may also be used.

5) In patients with acute bleeding from $\mathrm{PHG}$, vasoactive drugs (TL, SMT or OCT) can be administered, although data are scarce on its efficacy. Traditional NSBB should be introduced once the acute bleeding is controlled. There is no role for vasoactive drugs or NSBB for treatment of GAVE.

6) Preferably TIPS, or shunt surgery can be tried as a last resort for patients with PHG refractory to standard treatment, but there is no role for them in treatment of GAVE.

\section{Management of gastric and ectopic varices}

1) There are no data regarding primary prophylaxis of bleeding from gastric varices. As Traditional NSBB reduces portal pressure, they are an acceptable treatment option.

2) The recommendations for management of type $1 \mathrm{GOV}$ are the same as for esophageal varices.

3) Cyanoacrylate endoscopic injection is the preferred treatment of bleeding caused by type $2 \mathrm{GOV}$ and type $1 \mathrm{IGV}$. Traditional NSBB should be introduced after bleeding is controlled. However, as cyanoacrylate endoscopic injection can induce fatal thromboembolic events, it should be avoided in patients with hepatopulmonary syndrome and intracardiac shunts.
4) TIPS should be considered as a rescue therapy if active or recurrent bleeding cannot be controlled.

5) Balloon occluded retrograde transvenous obliteration (BRTO) and endoscopic ultrasound-guided coil and cyanoacrylate injection may be used in selected patients with gastric varices and active or recurrent bleeding, but these methods have not gained widespread application due to scarcity of data recommending their employment. They also require equipment and expertise that few centers have.

6) There are insufficient data to make a recommendation concerning ectopic varices, including IGV type 2. Depending on variceal size, cyanoacrylate endoscopic injection, band ligation, endoscopic ultrasound-guided coil and cyanoacrylate injection, TIPS and BRTO can be used.

\section{Management of PH in patients with extrahepatic portal} vein obstruction

1) For chronic extrahepatic portal vein obstruction (EHPVO), there is insufficient evidence to recommend traditional NSBB or endoscopic treatment for primary prophylaxis of VB. Both treatment options are acceptable for patients at risk of bleeding.

2) In the absence of specific data, management of acute VB should follow the same measures currently employed in management of cirrhosis, including vasoactive drugs and EVL.

3) EVL or traditional NSBB may be used as secondary prophylaxis, because they are safe and efficient. There are no data that support the use EVL and NSBB in combination to prevent recurrent bleeding in EHPVO.

4) In chronic EHPVO, anticoagulation, whenever indicated, should be started after adequate prophylaxis for VB.

\section{Management of schistosomal PH}

1) In PH caused by schistosomiasis, there are few data that suggest the efficacy of traditional NSBB or EVL as primary prophylaxis of VB. However, both strategies are currently used for patients at risk of bleeding. SCL must be avoided in patients that have not already had a bleeding event.

2) While there is a lack of data, the same treatment options used to control acute VB in cirrhosis can be used by analogy on patients with $\mathrm{PH}$ caused by schistosomiasis.

3) For secondary prophylaxis of VB, either EVL alone or a combination of EVL and traditional NSBB are acceptable, but the evidence for their use is not strong. SCL may be used if EVL is not available or not feasible.

4) There are no data to recommend surgery over EVL or traditional NSBB for secondary prophylaxis in PH due to schistosomiasis. Due to its efficacy and safety, EVL alone or in combination with traditional NSBB is recommended. Surgery is recommended as rescue therapy if endoscopic or combined treatment fails.

5) Surgical treatment options influence clinical outcomes. Azygos-portal devacularization with splenectomy is the preferred surgical procedure for $\mathrm{PH}$ caused by schistosomiasis. Postoperative endoscopic treatment improves variceal eradication and decreases bleeding recurrence.

\section{Authors' contributions}

Bittencourt PL, Strauss E, Farias AQ and Mattos AA reviewed data and updated the recommnedations. Lopes EP made the final critical revision of the manuscript. 
Bittencourt PL, Strauss E, Farias AQ, Mattos AA, Lopes EP. Sangramento varicoso: atualização das recomendações da Sociedade Brasileira de Hepatologia. Arq Gastroenterol. 2017;54(4):349-55.

RESUMO - Desde a publicação em 2010 das recomendações da Sociedade Brasileira de Hepatologia sobre a prevenção e tratamento do sangramento varicoso, novos dados baseados em evidências científicas foram publicados na literatura, mudando o manejo atual da hipertensão portal. O objetivo deste manuscrito foi atualizar as recomendações prévias da SBH, levando em consideração o novo conceito de estadiamento prognóstico da cirrose individualizando seu manejo de acordo com a presença de fibrose avançada, cirrose compensada ou descompensada. Um grupo de cinco experts revisou todas as recomendações de acordo com os dados publicados na literatura e elaborou um manuscrito submetido subsequentemente à apreciação e revisão de todos os membros da Sociedade Brasileira de Hepatologia via homepage da sociedade. As recomendações finais revisadas foram condensadas no presente documento.

DESCRITORES - Hemorragia gastrointestinal. Varizes esofágicas e gástricas. Cirrose hepática. Infecção.

\section{REFERENCES}

1. Abraldes JG, Albillos A, Banares R, Turnes J, Gonzalez R, Garcia-Pagan JC, et al. Simvastatin lowers portal pressure in patients with cirrhosis and portal hypertension: a randomized controlled trial. Gastroenterology. 2009;136:1651-8.

2. Abraldes JG, Villanueva C, Aracil C, Turnes J, Hernandez-Guerra M, Genesca J, et al. Addition of simvastatin to standard therapy for the prevention of variceal rebleeding does not reduce rebleeding but increases survival in patients with cirrhosis. Gastroenterology. 2016;150:1160-70.

3. Bang UC, Benfield T, Hyldstrup L, Jensen JB, Bendtsen F. Effect of propranolol on survival in patients with decompensated cirrhosis: a nationwide study based Danish patient registers. Liver Int. 2016;36:1304-12.

4. Binmoeller KF, Weilert F, Shah JN, Kim J. EUS-guided transesophageal treatment of gastric fundal varices with combined coiling and cyanoacrylate glue injection (with videos) Gastrointest Endosc. 2011;74:1019-25.

5. Bittencourt PL, Farias AQ, Strauss E, Mattos AA, Pannel of the 1st Brazilian Consensus of Variceal Bleeding, Brazilian Society of Hepatology. Variceal bleeding: consensus meeting report from the Brazilian Society of Hepatology. Arq Gastroenterol. 2010;47:202-16.

6. Bossen L, Krag A, Vilstrup H, Watson H, Jepsen P. Nonselective beta-blockers do not affect mortality in cirrhosis patients with ascites: post hoc analysis of three RCTs with 1198 patients. Hepatology. 2016;63:1968-76.

7. Brunner F, Berzigotti A, Bosch J. Prevention and treatment of variceal haemorrhage in 2017. Liver Int. 2017;37 Suppl 1:104-15.

8. Castera L, Pinzani M, Bosch J. Non invasive evaluation of portal hypertension using transient elastography. J Hepatol. 2012;56:696-703.

9. Costa Lacet CM, Neto JB, Ribeiro LT, Oliveira FS, Wyszomirska RF, Strauss E. Schistosomal portal hypertension: Randomized trial comparing endoscopic therapy alone or preceded by esophagogastric devascularization and splenectomy. Ann Hepatol. 2016;15:738-44.

10. D’Amico G, Pasta L, Morabito A, D’Amico M, Caltagirone M, Malizia G, et al. Competing risks and prognostic stages of cirrhosis: a 25 -year inception cohort study of 494 patients. Aliment Pharmacol Ther. 2014;39:1180-193.

11. de Franchis R; Baveno V Faculty. Expanding consensus in portal hypertension. Report of the Baveno VI Consensus Workshop: stratifying risk and individualizing care for portal hypertension. J Hepatol. 2015;63:743-52.

12. de Mattos AZ, de Mattos AA. The Baveno VI criteria to identify patients not requiring endoscopic surveillance for esophageal varices - Should we use it? J Hepatol. 2017;66:1327-33.

13. Garcia-Pagan JC, Caca K, Bureau C, Laleman W, Appenrodt B, Luca A, et al.; Early TIPS (Transjugular Intrahepatic Portosystemic Shunt) Cooperative Study Group. Early use of TIPS in patients with cirrhosis and variceal bleeding. N Engl J Med. 2010;362:2370-2379.

14. Garcia-Pagan JC, Di Pascoli M, Caca K, Laleman W, Bureau C, Appenrodt B, et al. Use of early-TIPS for high-risk variceal bleeding: results of a post-RCT surveillance study. J Hepatol. 2013;58:45-50.

15. Garcia-Tsao G, Abraldes JG, Berzigotti A, Bosch J. Portal hypertensive bleeding in cirrhosis: Risk stratification, diagnosis, and management: 2016 practice guidance by the American Association for the study of liver diseases. Hepatology. 2017;65:310-35.

16. Henry Z, Uppal D, Saad W, Caldwell S. Gastric and ectopic varices. Clin Liver Dis. 2014;18:371-88.

17. Kallini JR, Gabr A, Kulik L, Ganger D, Lewandowski R, Thornburg B, Salem R. Noncirrhotic complete obliterative portal vein thrombosis: Novel management using trans-splenic transjugular intrahepatic portosystemic shunt with portal vein recanalization. Hepatology. 2016;63:1387-90.
18. Leithead JA, Rajoriya N, Tehami N, Hodson J, Gunson BK, Tripathi D, et al. Non-selective beta-blockers are associated with improved survival in patients with ascites listed for liver transplantation. Gut. 2015;64:1111-19.

19. Madsen BS, Nielsen KF, Fialla AD, Krag A. Keep the sick from harm in spontaneous bacterial peritonitis: Dose of beta blockers matters. J Hepatol. 2016;64:1455-6.

20. Mandorfer M, Bota S, Schwabl P, Bucsics T, Pfisterer N, Kruzik M, et al. Nonselective beta blockers increase risk for hepatorenal syndrome and death in patients with cirrhosis and spontaneous bacterial peritonitis. Gastroenterology. 2014; 146:1680-90.

21. Mookerjee RP, Pavesi M, Thomsen KL, Mehta G, MacNaughtan J, Bendtsen F, et al.; CANONIC Study Investigators of the EASL-CLIF Consortium. Treatment with nonselective beta-blockers is associated with reduced severity of systemic inflammation and improved survival of patients with acute-on-chronic liver failure. J Hepatol. 2016;64:574-82.

22. Reiberger T, Ulbrich G, Ferlitsch A, Payer BA, Schwabl P, Pinter M, et al. Carvedilol for primary prophylaxis of variceal bleeding in cirrhotic patients with haemodynamic non-response to propranolol. Gut. 2013;62:1634-41.

23. Rudler M, Cluzel P, Corvec TL, Benosman H, Rousseau G, Poynard T, et al. Early-TIPS placement prevents rebleeding in high-risk patients with variceal bleeding, without improving survival. Aliment Pharmacol Ther. 2014;40: 1074-80.

24. Seo YS, Park SY, Kim MY, Kim JH, Park JY, Yim HJ, et al. Lack of difference among terlipressin, somatostatin, and octreotide in the control of acute gastroesophageal variceal hemorrhage. Hepatology. 2014;60:954-63.

25. Serste T, Francoz C, Durand F, Rautou PE, Melot C, Valla D, et al. Beta-blockers cause paracentesis-induced circulatory dysfunction in patients with cirrhosis and refractory ascites: a crossover study. J Hepatol. 2011;55:794-99.

26. Serste T, Melot C, Francoz C, Durand F, Rautou PE, Valla D, et al. Deleterious effects of beta-blockers on survival in patients with cirrhosis and refractory ascites. Hepatology. 2010;52:1017-22.

27. Shah HA, Azam Z, Rauf J, Abid S, Hamid S, Jafri W, et al. Carvedilol vs. esophageal variceal band ligation in the primary prophylaxis of variceal hemorrhage: a multicentre randomized controlled trial. J Hepatol. 2014;60:757-64.

28. Smith LA, Morris AJ, Stanley AJ. The use of hemospray in portal hypertensive bleeding; a case series. J Hepatol. 2014;60:457-60.

29. Tandon P, Abraldes JG, Keough A, Bastiampillai R, Jayakumar S, Carbonneau $\mathrm{M}$, et al. Risk of bacterial infection in patients with cirrhosis and acute variceal hemorrhage, based on Child-Pugh class, and effects of antibiotics. Clin Gastroenterol Hepatol. 2015;13:1189-96.

30. Thornburg B, Desai K, Hickey R, Kulik L, Ganger D, Baker T, Abecassis M, Lewandowski RJ, Salem R. Portal Vein Recanalization and Transjugular Intrahepatic Portosystemic Shunt Creation for Chronic Portal Vein Thrombosis: Technical Considerations. Tech Vasc Interv Radiol. 2016;19:52-60.

31. Tripathi D, Ferguson JW, Kochar N, Leithead JA, Therapondos G, McAvoy NC, et al. Randomized controlled trial of carvedilol versus variceal band ligation for the prevention of the first variceal bleed. Hepatology. 2009;50:825-33.

32. Villanueva C, Colomo A, Bosch A, Concepcion M, Hernandez-Gea V, Aracil $\mathrm{C}$, et al. Transfusion strategies for acute upper gastrointestinal bleeding. N Engl J Med. 2013;368:11-21.

33. Wells M, Chande N, Adams P, Beaton M, Levstik M, Boyce E, et al. Meta-analysis: vasoactive medications for the management of acute variceal bleeds. Aliment Pharmacol Ther. 2012;35:1267-78. 